\title{
The Effect of Self-management and Exercise Immersion on Physical Self-awareness among the Elderly Participating in Sports Activities
}

\author{
Yeong-Gwon Jo, Professor, Dept. of Physical Education, Gwangju University of Education,Gwangju,61204, \\ Korea. \\ Jeong-Sun Kim, Professor, Dept. of Taekwondo and Physical Education, Vison College,Jeonju, 55069, Korea. \\ *Chun-Ho Yang, Professor, Dept. of Marine Sports, Hanseo University, Seosan 31962, Korea, \\ healthyang@hanseo.ac.kr \\ ${ }^{*}$ Corresponding author
}

\begin{abstract}
The aim of this study is to examine the effect of self-management and exercise immersion on physical self-awareness among the elderly participating in sports activities. This study set those who are 65 years old or over and who regularly participate in sports activities as its population. Sampling was conducted by a random sampling method among non-probability sampling methods. Respondents were asked to respond to the questions on the questionnaire by themselves. After excluding some copies that were not sincerely filled out, 331 copies in total were used for the final analysis. The results obtained through this research process are as follows. First, self-management and exercise immersion have partial positive relationships with physical self-awareness among old people participating in sports activities. Second, self-management has a partial and positive effect on physical self-awareness among old people participating in sports activities. Third, exercise immersion has a partial and positive effect on physical self-awareness among old people participating in sports activities. The above findings prove that selfmanagement and exercise immersion are important elements that affect physical self-awareness among old people participating in sports activities. In particular, given that management of body, a sub-variable of self-management, and cognitive commitment, a sub-variable of exercise immersion, have positive effects on physical self-awareness, voluntary participation in sports activities of old people leads to positive physical self-awareness.
\end{abstract}

Keywords: Self-management, Exercise immersion, Physical function, Physical fitness, Self-awareness. Received: 07.12.2020 Accepted: 10.01.2021 $\quad$ Published: 08.02.2021

\section{INTRODUCTION}

The elderly face a number of difficulties in daily life, including psychological confusion caused by a loss of public roles and changes in family relations as well as physical aging. Elderly people who face more than one of these problems at once suffer even more. This suffering can lead to depression, leaving home, and even suicide [1]. To address the problems faced by the elderly, many studies have examined the ways they can live healthy lives. One of the ways the elderly can overcome their difficulties is through participation in sports activities. Sports activities can provide the elderly with psychological well-being, satisfaction with personal desire, satisfaction with life in old age, and happiness in life [2].

Continuing sports activities into old age can help a person age successfully [3]. To best enjoy sports activities, they need to practice self-management. Self-management is a process in which one uses various skills and strategies to change their own behavior [4]. The ability to manage oneself has a positive effect on continuous participation in sports activities [5,6].

Aside from basic movement necessary for survival, there are a wide variety of physical activities that can be considered sports activities, A large number of people participate in sports activities, even if they do not participate in them professionally. Participation in sports activities allows one to experience personal specific experiences and optimal moments. The state in which a person is completely immersed in a task as self-motivated activity is called immersion or optimal experience[7]. Immersion is used to mean a faithful adaptation to or obsession with something; someone who is immersed in an activity feels that he or she perfectly controls his or her activity, and that there is no border between themselves and the environment [8]. While sports situations provide participants with various environments and situations to experience immersion, most sports participants find it difficult to experience or understand moments of immersion. 
In modern society, the degree to which an individual perceives themselves to be a valuable person is an important element of leading a successful life. That is, self-perception can be said to be the most essential structure to promote and mediate human behavior in human cognition. Having a positive physical selfperception is an important element which makes a participant in sports activities immerse themselves in sports and produce optimal performance by controlling their negative feelings and stress by themselves [9].

In perceiving one's body and doing sports activities, it is as important to manage oneself as it is to immerse oneself in sports. In golf, self-management has been defined as the ability to regulate and maintain oneself, which makes one display their best skills [10]. Strict self-management allows one to achieve what one intends, resulting in good game performance [11]. For the elderly, participating in sports can allow one to immerse themselves in sports and produce the best results through the process of controlling and overcoming their negative emotions and stress. As described above, while selfmanagement and sports immersion are the elements affecting physical self-perceptions of the elderly, there is a lack of research on the topic.

Old people who participate in sports make substantial efforts to live happy lives through health promotion. For the elderly, participating in sports activities will improve their happiness and life quality by improving their self-perceptions of their bodies. Consequently, this study set self-management and sports immersion as variables that help them improve their sports levels, and aimed to examine the relationship among those variables and physical self-perception.

\section{Research Methods}

\subsection{Research objects}

This study set those who are 65 years old or over and who regularly participate in sports activities as its population. Sampling was conducted by a random sampling method among non-probability sampling methods. Respondents were asked to respond to the questions on the questionnaire by themselves. Excluding some copies of the questionnaire which were not filled out properly, this study ultimately used 331 copies in total for the final analysis of the data. The general characteristics of the respondents are listed in [Table 1].

Table 1 General characteristics of respondents

\begin{tabular}{llll}
\hline Variable & Classification & N. & $\%$ \\
\hline \multirow{2}{*}{ Gender } & Male & 169 & 55.1 \\
& Female & 162 & 48.9 \\
& Married & 201 & 60.7 \\
& Single & 130 & 39.3 \\
Event & Marathon/Jogging & 59 & 17.8 \\
& Gate ball & 74 & 22.4 \\
& Aerobic/Dance & 56 & 16.9 \\
& Mountaineering & 95 & 28.7 \\
Monthly income & Football & 47 & 14.2 \\
& Less than 1 mil. & 75 & 22.6 \\
& 1 mil. - less than 2 mil. & 81 & 24.5 \\
Sum & 2 mil. - less than 3 mil. & 96 & 29.0 \\
\hline
\end{tabular}

\subsection{Measurement tools}

\subsubsection{Self-management}

In this study, the scale used to measure self-management is the Athletes' Self-Management Questionnaire (ASMQ) developed by [12] and used by [13,14], and others. This study revised the questionnaire to the aim of this study. The scale is a 5-point Likert scale ranging from 1 point ('Definitely no') to 5 points ('Definitely yes').

\subsubsection{Sports commitment}


The scale used to measure sports commitment in this study was the Expansion of Sports Commitment Model (ESCM) developed by [15]. It has been used by [16,17], and [18], among others. This study revised it to the aim of this study. The scale is the 5-point Likert scale described above.

\subsubsection{Physical self-awareness}

The scale used to measure physical self-awareness in this study was an open-ended questionnaire originally developed by [19] and that has been used by [20]. This study revised it to the aim of this study. The scale is the 5-point Likert scale described above.

\subsection{Validity and reliability}

To test the validity of the measurement tools, this study conducted a principal component analysis of exploratory factor analysis. To simplify the factor structure, it used varimax among the orthogonal rotation methods. The criterion to extract a common factor was an eigenvalue of 1.0 or over. Factor loading of .50 or over was accepted. To test the reliability of the measurement tools, Cronbach's $\alpha$ coefficient according to internal consistency was used.

\subsubsection{Self-management}

Table 2 Validity and reliability of self-management

\begin{tabular}{lllll}
\hline Question & $\begin{array}{l}\text { Management } \\
\text { human relations }\end{array}$ & $\begin{array}{c}\text { ofManagement } \\
\text { of training }\end{array}$ & $\begin{array}{l}\text { Management } \\
\text { of body }\end{array}$ & $\mathrm{h}^{2}$ \\
\hline Q 04 & $\mathbf{. 8 9 8}$ & .002 & -.029 & .718 \\
Q 03 & $\mathbf{. 8 7 5}$ & .138 & .066 & .720 \\
Q 05 & -.023 & .892 & -.070 & .790 \\
Q 06 & .169 & .861 & .093 & .806 \\
Q 02 & .013 & .037 & .848 & .801 \\
Q 01 & .020 & -.020 & .847 & .778 \\
\hline Eigenvalue & 1.846 & 1.440 & 1.326 & \\
Variance \% & 30.773 & 23.997 & 22.096 & \\
Cumulative $\%$ & 30.773 & 54.770 & 76.886 & .790 \\
\hline Reliability & .804 & .876 & & \\
\hline
\end{tabular}

KMO $=.522, \chi^{2}=354.659, \mathrm{df}=15, p=.001$

As shown in [Table 2], Bartlett's test of sphericity for self-management resulted in a value of 354.659, its significance probability was .001, and its KMO index was .522. The factor analysis for the six questions on self-management generated three factors, which explain about $76.9 \%$ of the total variance. The factor loadings of self-management were as follows: .875 .898 for management of human relations; .861 .892 for management of training; and .847 .848 for management of body. The reliability values for selfmanagement were as follows: .804 for management of human relations; .876 for management of human training; and .790 for management of body.

\subsubsection{Exercise immersion}

Table 3 Validity and reliability of exercise immersion

\begin{tabular}{llll}
\hline Question & Cognitive commitment & Behavioral commitment & $\mathrm{h}^{2}$ \\
\hline Q 01 & $\mathbf{. 8 4 0}$ & -.005 & .700 \\
Q 02 & .837 & .007 & .706 \\
Q 03 & -.021 & .799 & .637 \\
Q 04 & .022 & .798 & .639 \\
\hline Eigenvalue & 1.406 & 1.276 & \\
Variance \% & 35.158 & 31.890 & \\
Cumulative \% & 35.158 & 67.048 & \\
\hline Reliability & .737 & .780 & \\
\hline
\end{tabular}

KMO $=.482, \chi^{2}=88.136, \mathrm{df}=6, p=.001$ 
As shown in [Table 3], Bartlett's test of sphericity for exercise immersion resulted in a value of 354.659, its significance probability was .001, and its KMO index was .522. The factor analysis for four questions on exercise immersion generated two factors, which explain about $67.0 \%$ of the total variance. The factor loadings of exercise immersion were as follows: .837 .840 for cognitive commitment and .798 .799 for behavioral commitment. The reliability values for exercise immersion were as follows: .737 for cognitive commitment and .780 for behavioral commitment.

\subsubsection{Physical self-awareness}

Table 4 Validity and reliability of physical self-awareness

\begin{tabular}{|c|c|c|c|c|}
\hline Question & Physical function & On body & Health & $\mathrm{h}^{2}$ \\
\hline $\bar{Q} 01$ & .766 & .054 & .103 & .620 \\
\hline Q 02 & .629 & .262 & -.049 & .557 \\
\hline Q 03 & .622 & .206 & .215 & .504 \\
\hline Q 04 & .504 & .071 & .345 & .598 \\
\hline Q 05 & .030 & .782 & .090 & .545 \\
\hline Q 06 & .318 & .622 & .128 & .728 \\
\hline Q 07 & .237 & .610 & .166 & .567 \\
\hline Q 08 & .293 & -.120 & .792 & .577 \\
\hline Q 09 & .016 & .342 & .654 & .575 \\
\hline Q 10 & .094 & .377 & .589 & .600 \\
\hline Eigenvalue & 3.191 & 1.078 & 1.002 & 1.002 \\
\hline Variance $\%$ & 31.909 & 10.776 & 10.018 & 10.018 \\
\hline Cumulative \% & 31.909 & 42.685 & 52.703 & 52.703 \\
\hline Reliability & .793 & .804 & .809 & \\
\hline
\end{tabular}

$\mathrm{KMO}=.818, \chi^{2}=530.794, \mathrm{df}=45, p=.001$

As shown in [Table 4], Bartlett's test of sphericity for physical self-awareness resulted in a value of 530.794, its significance probability was .001, and its KMO index was .818. The factor analysis for 10 questions on exercise immersion generated three factors, which explain about $52.7 \%$ of the total variance. The factor loadings of physical self-awareness were as follows: .504 .766 for physical function; .610 .782 for on body; and .589 .792 for health. The reliability values for physical selfawareness were as follows: .793 for physical function; .804 for on body; and .809 for health.

\subsection{Data Processing}

Collected data were analyzed with the SPSS statistical program. To identify the normal distribution as well as the validity and reliability of the data, this study examined frequency distribution and conducted exploratory factor analysis and reliability testing. To examine the correlations and causal relationships among the variables, this study conducted correlation analysis and multiple regression analysis; the significance level was set at $\alpha=.05$.

Table 5 Correlations between self-management and physical self-awareness

\begin{tabular}{lllllll}
\hline Variable & $\mathrm{A}$ & $\mathrm{B}$ & $\mathrm{C}$ & $\mathrm{D}$ & $\mathrm{E}$ & $\mathrm{F}$ \\
\hline Management of human relations & - & & & & & \\
Management of training & $.158^{* *}$ & - & & & \\
Management of body & .042 & .025 & - & & \\
Physical function & .049 & -.034 & $.501^{* * *}$ & - & \\
On body & -.015 & .098 & $.393^{* * *}$ & $.444^{* * *}$ & - & \\
Health & .042 & -.022 & $.449^{* * *}$ & $.435^{* * *}$ & $.421^{* * *}$ & -
\end{tabular}


$* * * p<.001, * * p<.01$

\section{Results}

3.1. The correlations among self-management, exercise immersion, and physical self-awareness among the elderly participating in sports activities

\subsubsection{The correlations between self-management and physical self-awareness}

As shown in [Table 5], self-management and physical self-awareness, among the elderly participating in sports activities, are partially correlated. Specifically, management of body is positively correlated with physical function $(\mathrm{r}=.501, \mathrm{p}<.001)$, on body $(\mathrm{r}=.393, \mathrm{p}<.001)$, and health $(\mathrm{r}=.449, \mathrm{p}<.001)$.

Table 6 Correlations between exercise immersion and physical self-awareness

\begin{tabular}{llllll}
\hline Variable & $\mathrm{A}$ & $\mathrm{B}$ & $\mathrm{C}$ & $\mathrm{D}$ & $\mathrm{E}$ \\
\hline Cognitive commitment & - & & & & \\
Behavioral commitment & .001 & - & & & \\
Physical function & $.555^{* * *}$ & .042 &. & $.444^{* * *}$ & - \\
On body & $.413^{* * *}$ & .017 & $.435^{* * *}$ & $.421^{* * *}$ & - \\
Health & $.350^{* * *}$ & $.110^{*}$ & .4 \\
\hline
\end{tabular}

*** $p<.001,{ }^{*} p<.05$

3.1.2.Correlations between exercise immersion and physical self-awareness

As shown in [Table 6], exercise immersion and physical self-awareness among the elderly participating in sports activities are found to be partially correlated. Specifically, cognitive commitment is positively correlated with physical function $(\mathrm{r}=.555, \mathrm{p}<.001)$, on body $(\mathrm{r}=.413, \mathrm{p}<.001)$, and health $(\mathrm{r}=.350, \mathrm{p}<.001)$, while behavioral commitment is positively correlated with health $(\mathrm{r}=.110, \mathrm{p}<.05)$.

3.2. The effect of self-management on physical self-awareness among the elderly participating in sports activities

\subsubsection{The effect of self-management on physical function}

Table 7 The effect of self-management on physical function

\begin{tabular}{llllll}
\hline & $\mathrm{B}$ & $\mathrm{SE}$ & $\beta$ & $t$ & \\
\hline (Constant) & 1.439 & .216 & & $6.651^{* * *}$ & $\mathrm{~F}=37.198^{* * *}$ \\
Management of Human relations & .031 & .042 & .036 & .742 & $\mathrm{R}^{2}=.254$ \\
Management of training & -.031 & .029 & -.052 & -1.069 & adjusted $\mathrm{R}^{2}=.248$ \\
Management of body & .397 & .038 & .501 & $10.477^{* * *}$ & \\
\hline
\end{tabular}

$* * * p<.001$

As shown in [Table 7], self-management has a significant effect on physical function $(F=37.198, p<.001)$, and its explanatory power is about $25.4 \%\left(\mathrm{R}^{2}=.254\right)$ of the total variance. In terms of the Beta values of the relative effects of self-management on physical function, management of body has a positive effect on it $(\beta=.501, \mathrm{p}<.001)$.

\subsubsection{The effect of self-management on body}

Table 8 The effect of self-management on body

\begin{tabular}{llllll}
\hline & $\mathrm{B}$ & $\mathrm{SE}$ & $\beta$ & $t$ & \\
\hline (Constant) & 1.586 & .243 & & $6.528^{* * *}$ & $\mathrm{~F}=21.435^{* * *}$ \\
Management of human relations & -.043 & .047 & -.046 & -.907 & $\mathrm{R}^{2}=.164$ \\
Management of training & .060 & .032 & .096 & 1.871 & adjusted \\
Management of body & .330 & .043 & .393 & $7.757^{* * *}$ & $\mathrm{R}^{2}=.157$ \\
\hline
\end{tabular}

*** $p<.001$

As shown in [Table 8], self-management has a significant effect on body $(F=21.435, p<.001)$, and its explanatory power is about $16.4 \%\left(\mathrm{R}^{2}=.164\right)$ of the total variance. Regarding the Beta values of the relative effects of self-management on body, management of body has a positive effect on body $(\beta=.393$, 
$\mathrm{p}<.001)$.

\subsubsection{The effect of self-management on health}

Table 9 The effect of self-management on health

\begin{tabular}{llllll}
\hline & $\mathrm{B}$ & $\mathrm{SE}$ & $\beta$ & $t$ & \\
\hline (Constant) & 1.461 & .234 & & $6.252^{* * *}$ & $\mathrm{~F}=27.885^{* * *}$ \\
Management of Human relations & .026 & .045 & .029 & .571 & $\mathrm{R}^{2}=.204$ \\
Management of training & -.023 & .031 & -.038 & -.754 & adjusted $\mathrm{R}^{2}=.196$ \\
Management of body & .372 & .041 & .449 & $9.088^{* * *}$ & \\
\hline
\end{tabular}

*** $p<.001$

As shown in [Table 9], self-management has a significant effect on health $(\mathrm{F}=27.885, \mathrm{p}<.001)$, and its explanatory power is about $20.4 \%\left(\mathrm{R}^{2}=.204\right)$ of the total variance. Examining the Beta values of the relative effects of self-management on health, management of body has a positive effect on health $(\beta=.449$, $\mathrm{p}<.001$ )

3.3. The effect of exercise immersion on physical self-awareness among the elderly participating in sports activities

\subsubsection{The effect of exercise immersion on physical function}

Table 10 The effect of exercise immersion on physical function

\begin{tabular}{llllll}
\hline & $\mathrm{B}$ & $\mathrm{SE}$ & $\beta$ & $t$ & \\
\hline (Constant) & 1.192 .185 & & $6.443^{* * *}$ & $\mathrm{~F}=73.705^{* * *}$ \\
Cognitive commitment & .441 & .036 & .555 & $12.106^{* * *}$ & $\mathrm{R}^{2}=.310$ \\
Behavioral commitment & .039 & .043 & .042 & .920 & adjusted $\mathrm{R}^{2}=.306$ \\
\hline
\end{tabular}

*** $p<.001$

As shown in [Table 10], exercise immersion has a significant effect on physical function ( $F=73.705$, $\mathrm{p}<.001)$ and its explanatory power is about $31.0 \%\left(\mathrm{R}^{2}=.310\right)$ of the total variance. For the Beta values of the relative effects of exercise immersion on physical function, cognitive commitment has a positive effect on physical function $(\beta=.555, \mathrm{p}<.001)$.

\subsubsection{The effect of exercise immersion on body}

Table 11 The effect of exercise immersion on body

\begin{tabular}{llllll}
\hline & $\mathrm{B}$ & $\mathrm{SE}$ & $\beta$ & $T$ & \\
\hline (Constant) & 1.468 & .215 & & $6.826^{* * *}$ & $\mathrm{~F}=33.779^{* * *}$ \\
Cognitive commitment & .348 & .042 & .413 & $8.213^{* * *}$ & $\mathrm{R}^{2}=.171$ \\
Behavioral commitment & .016 & .050 & .017 & .330 & adjusted $\mathrm{R}^{2}=.166$ \\
\hline
\end{tabular}

*** $p<.001$

As shown in [Table 11], exercise immersion has a significant effect on body ( $F=33.779, p<.001)$, and its explanatory power is about $17.1 \%\left(\mathrm{R}^{2}=.171\right)$ of the total variance. Regarding the Beta values of the relative effects of exercise immersion on physical function, cognitive commitment has a positive effect on body $(\beta=.413, \mathrm{p}<.001)$.

\subsubsection{The effect of exercise immersion on health}

Table 12 The effect of exercise immersion on health

\begin{tabular}{llllll}
\hline & $\mathrm{B}$ & $\mathrm{SE}$ & $\beta$ & $t$ & \\
\hline (Constant) & 1.297 & .216 & & $5.992^{* * *}$ & $\mathrm{~F}=25.540^{* * *}$ \\
Cognitive commitment & .291 & .043 & .350 & $6.818^{* * *}$ & $\mathrm{R}^{2}=.135$ \\
Behavioral commitment & .107 & .050 & .110 & $2.138^{*}$ & adjusted $\mathrm{R}^{2}=.129$ \\
\hline
\end{tabular}

${ }^{* * *} p<.001,{ }^{*} p<.05$

As shown in [Table 12], exercise immersion has a significant effect on health $(F=25.540, p<.001)$, and its explanatory power is about $13.5 \%\left(\mathrm{R}^{2}=.135\right)$ of the total variance. In terms of the Beta values of the relative effects of exercise immersion on health, cognitive commitment has a positive effect on it $(\beta=.350$, $\mathrm{p}<.001)$, and behavioral commitment has the same type of effect $(\beta=.110, p<.05)$. 


\section{Discussion}

The aim of this study is to examine the effect of self-management and exercise immersion on physical selfawareness among the elderly participating in sports activities. The findings of the analysis can be discussed as follows in regard to existing studies, and some hints are provided to future researches as well.

In sports, self-management can be defined as the process through which one prepares and overcomes through the practice of self-discipline in their lives [21]. It was found that self-management has causal effects on physical self-awareness. Specifically, management of body has an effect on physical selfawareness, which seems to be caused by the fact that elderly people participating in sports activities look positively at their bodies. By contrast, those who are not attentive to their bodies seem to have difficulty maintaining their body power and body shape, which makes them look negatively at their bodies.

Accordingly, for elderly people participating in sports activities, adjusting their body conditions through continuous body management may lead them to experience feelings of physical attractiveness. This is the origin of a healthy life and will lead them to have confidence to maintain positive human relations. Body management, which requires continuous efforts and a long time, comes from a positive perception of one's own body [22], which is accepted by this study. There have been various studies examining the relationship between self-management and physical self-awareness, including a study examining college students majoring in music [23], a study testing a structural model using dancing majors [22], and a study using Taekwondo trainers as research targets [24], and all of these have proven a significant causal relationship between self-management and physical self-awareness, supporting the findings of this study. However, the problem of existing studies is that most of them deal with professional players, thus limiting the generalizability of the findings.

The significance of this study is that the relationship between self-management and physical selfawareness was tested among the elderly participating in sports activities. Exercise immersion is a temporary phenomenon, and if one stops the sports activity and returns to daily life, exercise immersion does not continue. However, such commitment helps one enjoy a positive and active life. While beginners in sports activities can experience exercise immersion, it is typically participants equipped with more than basic skills that tend to experience it. Such exercise immersion can have an effect on physical selfawareness.

What one feels of one's sense of being starts with self-awareness. Physical self-awareness is an element comprising the comprehensive concept of oneself together with the scholastic concept of oneself, the social concept of oneself, and the emotional concept of oneself. Accordingly, the examination of the effect of exercise immersion on physical self-awareness showed a significant effect of the former on the latter.

Specifically, it was found that cognitive commitment had a significant effect on physical self-awareness. This means that when an old person perceives that he or she participates in sports activities, he or she perceives feelings of physical function, physical ability, physical attractiveness, and health condition as well as physical appearance within themselves. The findings that exercise immersion of participants in dance sports has a positive effect on physical self-awareness [25] and that exercise immersion of adults 20 years old and above participating in leisure sports has a significant effect on physical self-awareness [9] prove the thesis. Based on the above findings, this study would like to point out that the relationship between exercise immersion and physical self-awareness is true regardless of the particular sporting event or the age of participants. Thus, this study proves that exercise immersion of old people will serve as the most important variable forming their physical self-awareness.

\section{Conclusion}

This study aimed to examine the effects of self-management and exercise immersion on physical selfawareness among old people participating in sports activities, and based on the findings of the analysis, it concludes the following.

First, self-management and exercise immersion have partial positive relationships with physical selfawareness among old people participating in sports activities. Specifically, management of body has positive effects on physical function, body, and health. Further, cognitive commitment has positive effects on physical function, body, and health, and behavioral commitment has a positive effect on health.

Second, self-management has a partial and positive effect on physical self-awareness among old people participating in sports activities. Specifically, management of body has positive effects on physical function, health, and body, in descending order.

Third, exercise immersion has a partial and positive effect on physical self-awareness among old people participating in sports activities. Specifically, cognitive commitment has positive effects on physical function, body, and health. in descending order. Cognitive commitment also has a positive effect on 
behavioral commitment.

The above findings prove that self-management and exercise immersion are important elements that affect physical self-awareness among old people participating in sports activities. In particular, given that management of body, a sub-variable of self-management, and cognitive commitment, a sub-variable of exercise immersion, have positive effects on physical self-awareness, voluntary participation in sports activities of old people leads to positive physical self-awareness.

\section{References}

[1] Chang, J. W., \& Lee, J. S. The work satisfaction's mediated effect analysis that emotional labor of eldly care providers affect depression. Senior Welfare Research. 2013; 59: 31-54.

[2] Gang, S. T., \& Jeong, C. G. An effect of leisure satisfaction on psychological happiness and life satisfaction for physical activities participation of the elderly. Korea sport society. 2015; 13(3): 145156.

[3] Kim, K. S., \& Lee, E. J. Relation between Leisure Sports' Activities among Older Adults on Activities of Daily Living and Successful Aging. The Korea Contents Society. 2010; 10(4): 424-432.

[4] Kim, S. I. Analysis of Self-management in Propensity to Participant of Dance Sports. Korea sport research. 2005; 16(5): 437-449.

[5] Kim, S. I., \& Oh, H. O. The Relationship Between Exercise Motivation and Self-management of Participants in Dance Sports. Journal of coaching development. 2006; 8(3): 121-139.

[6] Jeong, N. J., \& Lim, J. S. Study of Water Sports Participants' Self-management and Stress Coping. Korea sport society. 2017; 15(3): 13-20.

[7] Csikszentmihalyi, M. Flow The Psychology of Optimal Experience. NY: Harper \& Low; 1990.

[8] Compbell, R. N. The new science: Self-esteem psychology. Lanham, M. D.: University Press of America; 1984.

[9] Kwon, S. J., \& Jeon, H. S. The Study on Influences Among Sports Participants' Physical Self-Perception, Flow and Subjective Well-Being. Korean journal of physical education. 2012; 51(2): 87-96.

[10] Moon, J. Y., \& Jeon, B. G. The Overcome Strategy on Psychological and Physical Inhibitors for Professional Golfer. Korean Society of Sport Psychology. 2008; 19(2): 135-150.

[11] Hong, H. S., \& Kim, D. K. Relationships among KLPGA Players' Self-Management on Immersion in Games and Satisfaction with Games. The Korean Society of Sports Science. 2009; 18(3): 537-554.

[12] Hur, J. H. Structural Validation of Athletes' Self - Management Measurement and Cause and Effect Model Test. Unpublished doctor Dissertation, Chungang University; 2001.

[13] Choi, Y. R., Baek, S. I., \& Yoon, S. M. Impact of Self-Management on Sport Emotion and Sport Confidence in Sport-for-All Participants. Korea sport society. 2014; 12(4): 241-252.

[14] Yeom, D. S., \& Choi, Y. R. Influence of Self-Leadership on Self-Management and Self-Efficacy in Dancefor-All Participants. Korea sport society. 2017; 15(1): 165-174.

[15] Scanlan. T. K., \& Carpenter. P. J., Schmidt, G. W., \& Simon. J. P. The spot commitment model: Measurement development for the youth sport domain. Journal of Sport and exercise psychology. 1993; 15: 16-38.

[16] Ko, Y. J. The Effect of Achievement Goal Orientation on Sport Commitment \& Exercise Adherence Intention of the Participants of the Soccer Schools for Children. Journal of exercise rehabilitation. 2011;7(1): 57-68.

[17] Yoon, S. W., \& Kang, S. T. The Effect of the Class Satisfaction on Exercise Commitment and the Exercise Adherence Intention for the Participants in the Golf for General Education at a University. Journal of Golf Studies. 2014; 8(2): 99-112.

[18] Oh, H. O. Effects of Exercise Capacity on Exercise Flow and Exercise Addiction in Pilates and Yoga Participants. Korean journal of physical education. 2010; 49(6): 139-148.

[19] Marsh, H. W., Richards, G., Johnson, S., Roche, L., \& Tremayne, P. Physical self-description questionnaire: Psychometric properties and a multitrait multimethod analysis of relations to existing instruments. Journal of Sport and Exercise Psychology. 1994; 16: 270-305.

[20] Han, J. Y. The Reciprocal Relationship between Exercise Participation and Physical Self Perception. Unpublished doctor Dissertation, Ewha Womans University; 2005.

[21] Huh, J. H.. The Relationship Between Sport Goal Orientation And Athletic Self-Management. Korean Journal of Sport Science. 2004; 15(3): 127-135.

[22] Kwon, Y. K., Lee, D. H., \& Lee, J. H. The Verification of the Structural Model Concerning Selfmanagement, Physical Self-perception, and Performance Confidence Among the Dance Majors. Korean journal of physical education. 2010; 49(6): 149-160.

[23] Kim, S. C., \& An, J. U. Effect of Stage Anxiety Self-perception and Self-management on Affects in Musical Majors. Korean journal of physical education. 2010; 49(5): 149-161. 
[24] Lee, W. M., \& Shin, J. S. The Relationship between Self-Management, Physical Self Perception, Physical Self Efficacy and Performance Confidence in a Taekwondo Demonstration Member. The Korean Society of Sports Science. 2017; 26(4): 403-419.

[25] Lee, G. S., \& Shin, S. S. The Leisure and Life Satisfaction of Housewife Participated in Dance Sports. Korean Journal of Leisure, Recreation. 2000; 2: 73-92. 